\title{
Determination of selected phenolic acid and majoritarian avenanthramides in different varieties of naked oats (Avena sativa L.) grown in Slovakia
}

\author{
Katarína Kulichová ${ }^{1, \bigotimes}$, Mária Maliarová ${ }^{1}$, Jozef Sokol ${ }^{1}$, Katarína Lašáková ${ }^{1}$ \\ and Michaela Havrlentová ${ }^{2,3}$
}

${ }^{1}$ Department of Chemistry, Faculty of Natural Sciences, University of SS. Cyril and Methodius in Trnava, Nám. J. Herdu 2, Trnava, 917 01, Slovak Republic

${ }^{2}$ Department of Biotechnologies, Faculty of Natural Sciences, University of Ss. Cyril and Methodius in Trnava, Nám. J. Herdu 2, Trnava, 917 01, Slovak Republic

${ }^{3}$ Research Institute of Plant Production, National Agricultural and Food Centre, Bratislavská cesta 122, Piešt’any, 921 68, Slovak Republic

\section{Article info}

\section{Article history:}

Received: $11^{\text {th }}$ November 2018

Accepted: $17^{\text {th }}$ December 2018

\section{Keywords:}

HPLC -DAD

Avenanthramides

Phenolic Acids

Oats

\begin{abstract}
Oats are important cereals. Oats are a good source of protein and lipids, polyphenolics, phenolic acids, flavonoids and avenanthramides. Avenanthramides is phenolic group, which is unique in oats and have antioxidant activity, anti-inflammatory, anti-atherogenic and anti-proliferative effect. The aim of study is determination of the majoritarian avenanthramides $(2 c, 2 p$ and $2 f$ ) and phenolic acids ( $p$-coumaric and ferulic) in selected varieties of oat (Avena sativa L.) grown in two consecutive years using the HPLC method. The oats were exposed to ultrasound supported extraction (two 15 min cycles). The simultaneous separation was performed using C18 type of stationary phase. The method showed a good linearity in the concentration range $0.04-5.24 \mu \mathrm{g} / \mathrm{mL}$ for $p$-coumaric acid, $0.04-$ $5.13 \mu \mathrm{g} / \mathrm{mL}$ for ferulic acid, $0.19-24.5 \mu \mathrm{g} / \mathrm{mL}$ for avenanthramide $2 \mathrm{c}, 0.53-$ $17.1 \mu \mathrm{g} / \mathrm{mL}$ for avenanthramide $2 \mathrm{p}, 0.8-25.6 \mu \mathrm{g} / \mathrm{mL}$ for avenanthramide $2 \mathrm{f}$. Correlation coefficients were higher than 0.9997. Detector operated at a wavelength $320 \mathrm{~nm}$. The repeatability of the method was evaluated in three concentration levels with satisfactory results for each analyte. The content of both phenolic acids is significantly lower (50- - 100-times) compared to the total content of avenanthramides in both years' harvests for all analyzed varieties. Content of total avenanthramides was the highest in varieties Racoon $(723.28 \mathrm{mg} / \mathrm{kg}$ ) followed by Oliver (578.59 mg/kg) and Kamil (384.17 mg/kg).
\end{abstract}

\section{Introduction}

Oats are cereals containing $\beta$-glucan, and are a good source of protein and lipids, several antioxidants (including e.g. vitamin E), phytic acid, sterols, polyphenolics, phenolic acids (PAs), flavonoids and avenanthramides (AVNs). These are concentrated in the outer gates layers (Menon et al.
2016). PAs and phenolic alkaloids, notably the AVNs, are present either in the 'free form' as soluble conjugates, or as insoluble bound forms (Shewry et al. 2008).

AVNs are a group of unique soluble bioactive compounds that are absent in other food crops. Oats contain a unique group of approximately 40 different types of AVNs that consist 
of an anthranilic acid derivatives and hydroxycinnamic acid derivatives (Boz 2015). AVNs from oats exhibit (potent) antioxidant activity in vitro and in vivo (Thomas et al. 2018). Amides of anthranilic acid are a group of naturally occurring phenolic amides in oats. Three avenantramides are most represented in the oat grains: $\quad \mathrm{N}$-[3', 4'-dihydroxy-(E)-cinnamoyl]-5hydroxyanthranilic acid (2c), N-[4'-hydroxy-(E)cinnamoyl]-5-hydroxyanthranilic acid (2p) and N-[4'-hydroxy-3'-methoxy-(E)-cinnamoyl]-5hydroxyanthranilic acid (2f) (Maliarová et al. 2015). Both animal studies and human clinical trials confirmed that oat antioxidants have the potential of reducing cardiovascular risks by lowering serum cholesterol, inhibiting LDL oxidation, they are anti-carcinogenic and attenuating platelet aggregation and peroxidation (Chen et al. 2004). Dietary AVNs supplementation increases antioxidant capacity in the biological tissues, thereby reduces steady-state formation of Reactive oxygen species and oxidative tissue damage (Li et al. 2017). Increasing the daily intake of whole grain cereals by $90 \mathrm{~g}$ has been associated with reduction in mortality from cardiovascular disease by $27 \%$, total cancer by $15 \%$, respiratory disease by $22 \%$, diabetes by $51 \%$ and infectious diseases by $26 \%$ (Whitehead et al. 2014).

It has been reported that gallic acid, vanillic acid, caffeic acid, ferulic acid, and $p$-coumaric acid are the main PAs in oats (Xu et al. 2009). Experiments in vitro have shown that AVNs have significant antioxidant capabilities, with 10- - 30-times higher radical scavenging activities than caffeic acid, ferulic acid, and vanillin (Emmons et al. 1999). For this reason, AVNs have become the subject of our study.

There are several studies that were focused on the identification and quantification of AVNs in oats, oat products, but also directly in clinical biological materials. In the study by $\mathrm{Chu}$ et al. (2013) the contents of AVNs in 7 oat varieties from Canada were reposted. Oats and products present data for oats from China were studied and published in several other studies (Ren et al. 2011; Li et al. 2017; Chen et al. 2018), husked oat from Finland (Multari et al. 2018).

Several studies assessed AVNs content in human materials such as plasma (Chen et al. 2007) and urine (Schär et al. 2018). However, data on content of AVNs in oats and oats products are still rather limited.

The aim of our study was the identification and quantification of AVNs as well as selected phenolic compounds: $p$-coumaric acid (PCA), ferulic acid (FA), avenanthramide 2c (AVN 2c), avenanthramide $2 p$ (AVN 2p) and avenanthramide $2 f(A V N 2 f)$ in oat varieties growing in Slovakia, in commercially available products from local markets and oatmeal and extruded oatbread.

\section{Experimental}

\section{Material}

Analyzed samples included 17 different oat varieties. In addition, 6 commercially available products $-4 \mathrm{x}$ oat flakes (Ravita, COOP Jednota, Vince, and the gluten free Kroner, all purchased from local market), $1 \mathrm{x}$ oat flour from new oat breading line (LO) (obtain from CELPO spol. s.r.o., Slovakia) and1x extruded oatbread.

Varieties of oat differ in their morphological, agronomical, phytopathological, and other characteristics. Oat was harvested in the summer of 2014, 2015 from the research field in the Research and Breeding Station at Vígl'aš-Pstruša, Slovakia $\left(48^{\circ} 32^{\prime} \mathrm{N}, 19^{\circ} 10^{\prime} \mathrm{E}\right)$.

The following varieties were included in the study - variety name (country of origin, year of harvest): 100260 CN (United Kingdom, 2014), Avenuda (Czech, 2014), Bayan 2 (China, 2014), Dunajec (PS - 191) (Slovakia, 2014), Hronec (PS - 166, 2014) (Slovakia, 2014), Kamil (Slovakia, 2014), Oliver (Slovakia, 2014), Racoon (United Kingdom, 2014), Tatran (Slovakia, 2014), Važec (PS - 176) (Slovakia, 2014), AC Percy (Canada, 2015), Avenuda (Czech, 2015), Avenuda x Atego (Slovakia, 2015), Expression (United Kingdom, 2015), Fussion (United Kingdom, 2015), Izák (Czech, 2015), Racoon (United Kingdom, 2015). All varieties of oat (Avena sativa L.) were provided by the Gene Bank of the Slovak Republic (Research Institute of Plant Production, Piešt'any, Slovakia). All varieties came from the same period of oat breeding in our region, originating from different countries as indicated below. 


\section{Preparation of extracts}

Samples of oat were milled by common laboratory mill $(120 \mathrm{~W}, 230 \mathrm{~V}, 50 \mathrm{~Hz}$ - the size of particles $5-10 \mu \mathrm{m})$. Samples of flour for each variety $(0.3 \pm 0.01 \mathrm{~g})$ were extracted by $2 \times 3 \mathrm{~mL} 70 \%(v / v)$ water solution of methanol at $55{ }^{\circ} \mathrm{C}$. The samples were extracted using ultrasound 2 x 15 min. The samples were then centrifuged at $6,500 \mathrm{~g}$ for $15 \mathrm{~min}$. The supernatants were kept at $-20{ }^{\circ} \mathrm{C}$ until HPLC analysis was carried out. The supernatants were immediately centrifuged repeatedly before analysis and then directly injected without dilution into the HPLC system. Extraction solutions (supernatants) were injected three times.

\section{HPLC analysis}

HPLC separation, identification and quantification was performed using Waters HPLC system (Waters, USA) equipped by Waters 1525 binary pump, Waters 2998 photodiode array (PDA) detector, Waters 2707 Autosampler, Thermostat Waters Model Column Heater 1500 Series, Waters Symmetry C18 column $(75 \times 4.6 \mathrm{~mm}$ i.d., $3.5 \mu \mathrm{m})$ with adequate security guard column and software Empower 2.

For gradient elution were prepared two phases, phase A was $0.1 \%$ water solution of formic acid and phase $\mathrm{B}$ was $0.1 \%$ methanol solution of formic acid. The gradient was non-linear: $0-8 \min 26 \%$ solvent $\mathrm{B}, 8-18 \mathrm{~min}$ of 42 to $45 \%$ solvent $\mathrm{B}$, $18-21$ min $100 \%$ solvent B. Similarly, the nonlinear gradient for phenolic compounds was used by authors Zeng et al. (2016). A flow rate was used of $1.0 \mathrm{~mL} / \mathrm{min}$. The column temperature was set at $35{ }^{\circ} \mathrm{C}$ and the injection volume was $20 \mu \mathrm{L}$. Detector operated at a wavelength $320 \mathrm{~nm}$.

\section{Validation of method}

For the validation of the HPLC-DAD method, parameters such as linearity, limits of detection (LOD), limits of quantification (LOQ), precision, and accuracy were evaluated. The calibration curves of analytes were constructed after injection of standard solutions (three concentration levels, three replicate injections of each solution). The LOD of the method were calculated as a signal to noise ratio of 3 using the injection of series of more diluted standard solutions of analytes. The LOQ were evaluated using signal to noise ratio of 10. Intra-day and inter-day precisions of the method were evaluated for three preparations of sample within one day and five days, making triplicate injections under the working conditions and (expressed as RSD \%).

\section{Results and Discussion}

\section{Extraction}

In the study Maliarová et al. (2015) were established the optimal conditions for the extraction of avenanthramides $2 \mathrm{c}, 2 \mathrm{p}$ and $2 \mathrm{f}$ from oat grain using response surface methodology (RSM). Sample extracts were prepared in $70 \%$ methanol. Comparison of retention times from HPLC and UV spectra of sample peaks and standards was used for identification of selected phenolic compounds in extracts of oats. Ultrasound supported extraction was proved most advantageous compared to Eppendorf Thermo-Mixer and to Environmental Shaker-Incubaton for PCA, FA and AVNs (Fig. 1). At the same time, optimal time of ultrasound supported extraction was investigated. The optimum extraction time was 2 times $15 \mathrm{~min}$ (Fig. 2). This extraction was showed maximum yield and short time of extraction. The advantages of using extraction of ultrasound in food and natural products were been published too by Chemat et al. (2017).

Results from extraction demonstrated, that for the following analysis of phenolic compounds: FA, PCA, AVN 2c, AVN 2p, AVN $2 f$ it is best to use ultrasound-supported extraction. Highest yield of phenolic compounds have been achieved in two time cycles for $15 \mathrm{~min}$ of sonification.

\section{HPLC analysis}

Reversed phase separation mode is most commonly used for HPLC separation of both PAs (PCA, FA) and AVNs. The work was focused on development of HPLC method for separation and determination of two PAs and three AVNs (2c, 2p, 2f). 


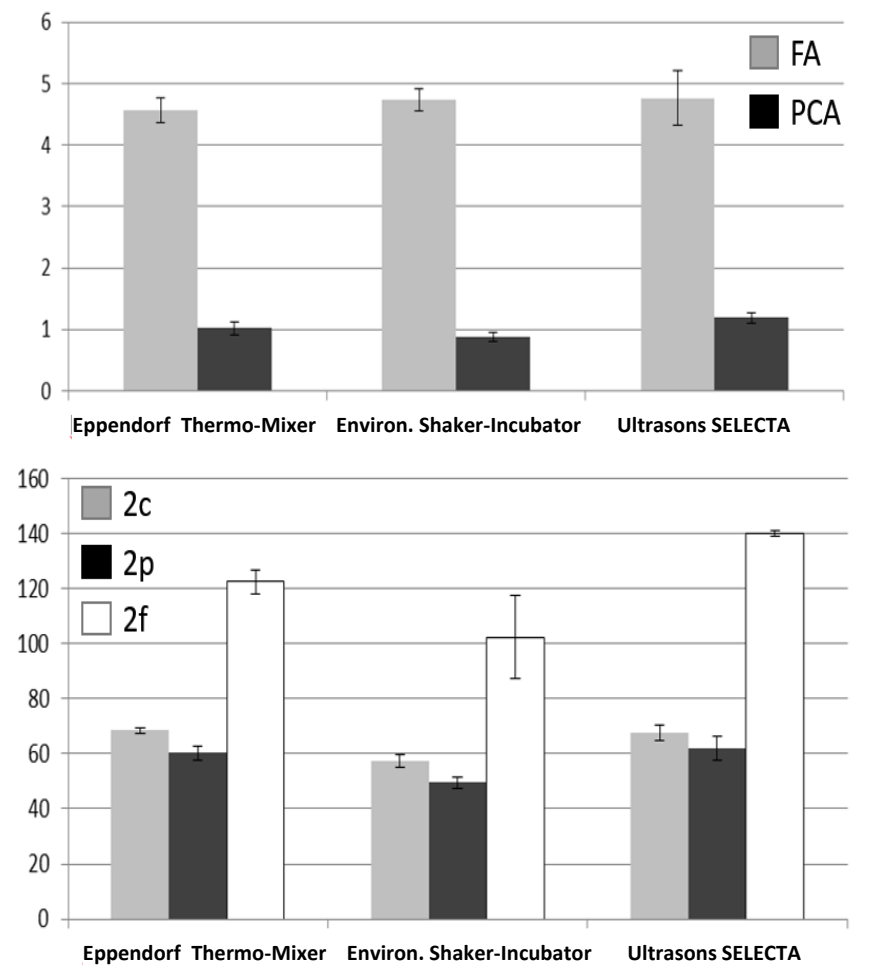

Fig. 1. Used extraction techniques for the determination of phenolic compounds $(\mathrm{mg} / \mathrm{kg})$ : ferulic acid (FA), $p$-coumaric acid (PCA), avenanthramide 2c (2c), avenanthramide $2 p(2 p)$, avenanthramide $2 f(2 f)$ (from three replicates).

For separation of phenolic compounds was used analytical column Symmetry C18 (75 x $4.6 \mathrm{~mm}$; $3.5 \mu \mathrm{m})$. The mobile phase consisted of methanol with formic acid and ultra pure water with formic acid. The gradient was non-linear. Similarly, the non-linear gradient for phenolic compounds was used by authors Zeng et al. (2016). Gradient elution profiles were investigated, which resulted in effective separation of target compounds in analysis time less than $20 \mathrm{~min}$. Phenolic compounds allow UV absorbance. Spectrophotometric detection of PAs and AVNs was realised by DAD detector operated in the interval from 220 to $400 \mathrm{~nm}$, where the absorption maxima of target compounds are presented $(310 \mathrm{~nm}$ for PCA, $320 \mathrm{~nm}$ for FA, $340 \mathrm{~nm}$ for AVN 2c, 320 for AVN 2p and $330 \mathrm{~nm}$ AVN 2f). As a result, the $320 \mathrm{~nm}$ (excitation) wavelength was chosen for the purpose of this study (Fig. 3).

\section{Validation of method}

The analytical data were determined under optimized separation and detection conditions.
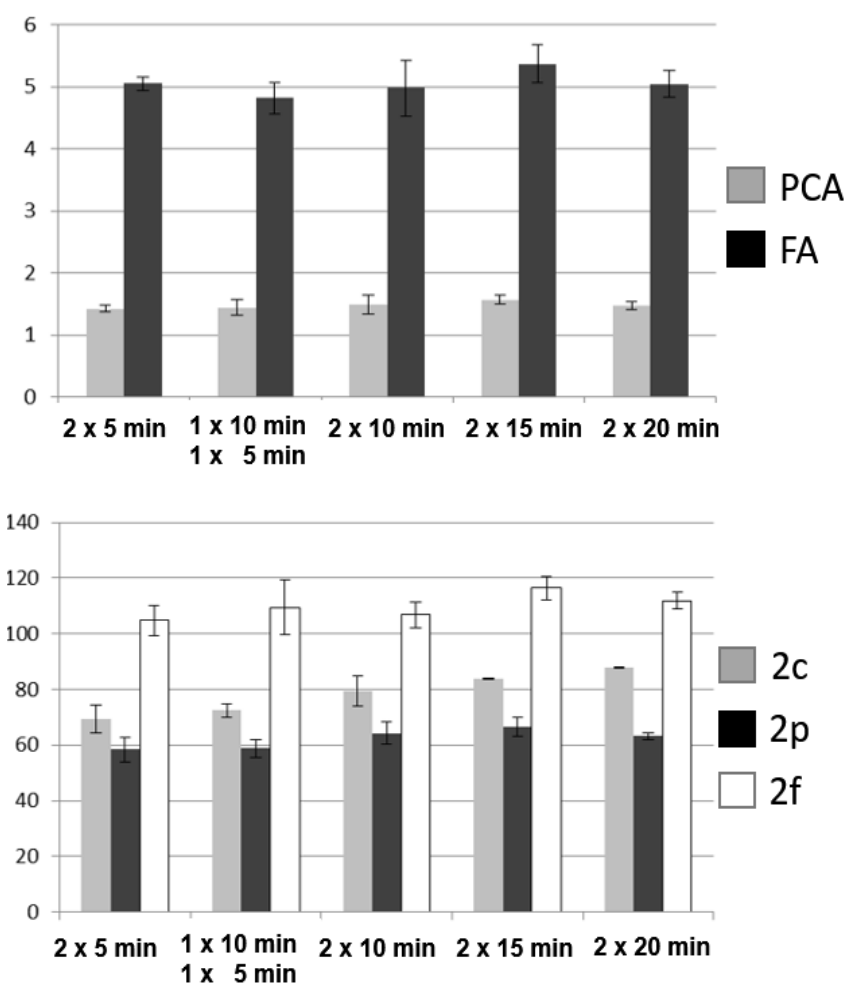

Fig. 2. Yield of phenolic compounds $(\mathrm{mg} / \mathrm{kg})$ : $p$-coumaric acid (PCA), ferulic acid (FA), avenanthramide 2c (2c), avenanthramide $2 \mathrm{p} \quad(2 \mathrm{p})$, avenanthramide $\quad 2 \mathrm{f} \quad(2 \mathrm{f})$ by Ultrasound supported extraction at various sonication time cycles (from four replicates).

Parameters including LOD, LOQ, and linear range were calculated to demonstrate the validation of the developed HPLC-DAD method. The calibration curves of the five analytes were created after the injection of a mixed standard solution. Results showed good linear relationship for each analyte (coefficient of determination in the range $0.9997-0.9999)$. The LOD of the method were calculated as a signal to noise ratio of 3 using the injection of series of more diluted standard solutions of analytes. The LOQ were evaluated using signal to noise ratio of 10 . LOD/LOQ of PCA was $18 / 68 \mathrm{ng} / \mathrm{mL}$; LOD/LOQ of FA was $28 / 101 \mathrm{ng} / \mathrm{mL}$; LOD/LOQ of AVN 2c was 20.3/88.8 $\mathrm{ng} / \mathrm{mL}$; LOD/LOQ of AVN $2 \mathrm{p}$ was $22.8 / 85.6 \mathrm{ng} / \mathrm{mL}$ and LOD/LOQ of AVN $2 \mathrm{f}$ was 28/108.8 ng/mL. Analytical parameters of the method used are listed in Table 1.

Intra-day precisions were evaluated for retention time in range $0.37-1.04 \%$ RSD and for area $0.47-2.18 \%$ RSD. Inter-day precisions (5 days) were evaluated for retention time in range $0.72-1.35 \%$ RSD and for area $1.19-3.09 \%$ RSD. 


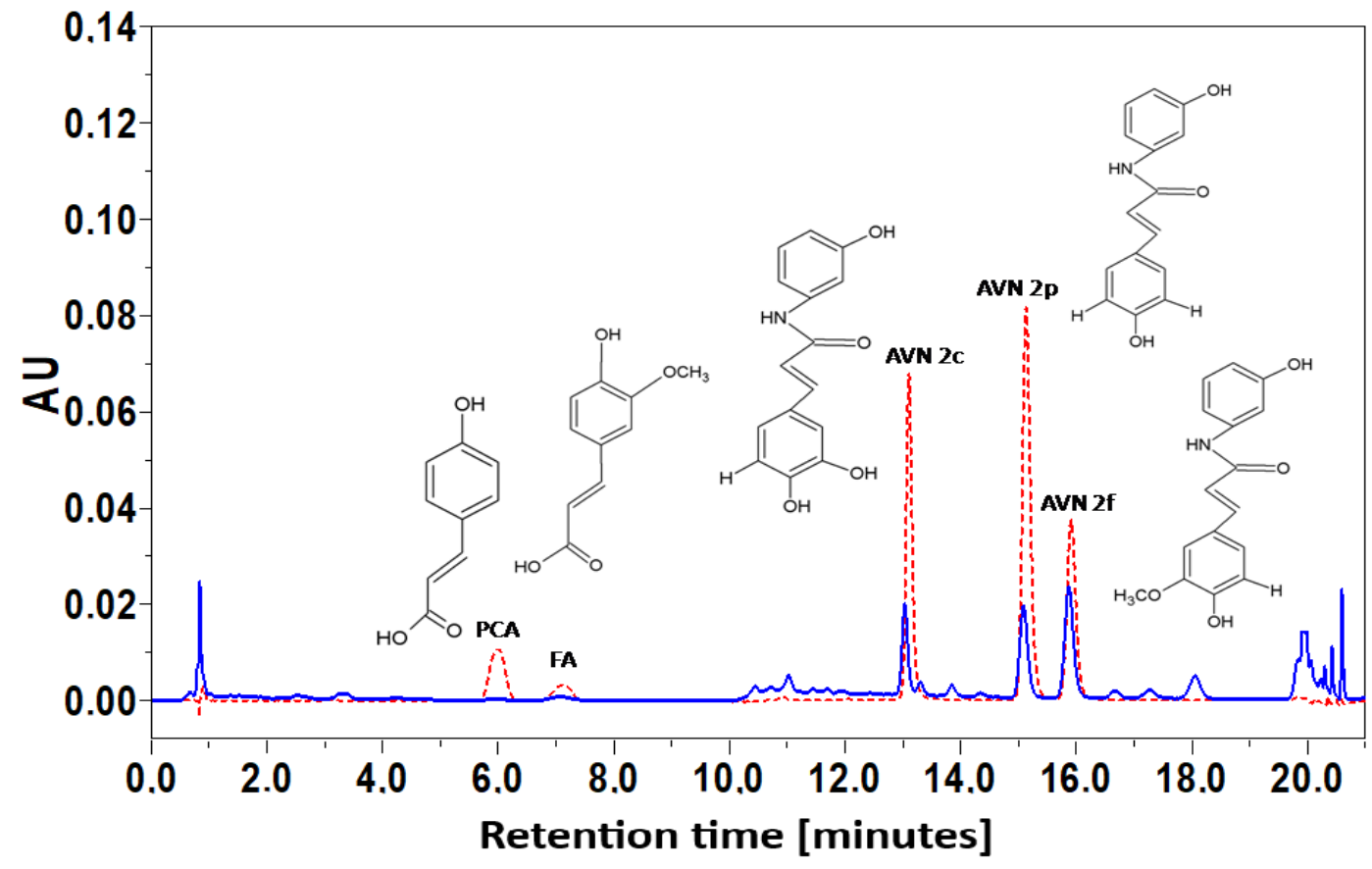

Fig. 3. Overlay of two chromatograms: separation of standard solution (red line) and real sample of oat variety Važec (blue line). Identified peaks are labelled by name and chemical structures of separated analytes.

Table 1. Analytical parameters of the HPLC method.

\begin{tabular}{llllll}
\hline Analyte & $\begin{array}{l}\text { Concentration range } \\
{[\boldsymbol{\mu g} / \mathbf{m L}]}\end{array}$ & $\begin{array}{l}\overline{\boldsymbol{t}}_{\mathbf{R}} \\
{[\mathbf{M i n}]}\end{array}$ & Regression equation & $\mathbf{R}^{\mathbf{2}}$ & $\begin{array}{l}\text { Wavelength } \\
{[\mathbf{n m}]}\end{array}$ \\
\hline PCA & $0.04-5.24$ & 6.19 & $\mathrm{y}=137780 \mathrm{x}-2282.3$ & 0.9998 & 320 \\
FA & $0.04-5.13$ & 7.41 & $\mathrm{y}=112910 \mathrm{x}-3019.3$ & 0.9999 & 320 \\
AVN 2c & $0.19-24.5$ & 13.49 & $\mathrm{y}=75748 \mathrm{x}-17047.0$ & 0.9998 & 320 \\
AVN 2p & $0.53-17.1$ & 16.17 & $\mathrm{y}=110824 \mathrm{x}-2944.8$ & 0.9999 & 320 \\
AVN 2f & $0.80-25.6$ & 17.22 & $\mathrm{y}=82557 \mathrm{x}-4287.9$ & 0.9997 & 320 \\
\hline
\end{tabular}

In Table 2 are listed values of determination of five studied polyphenols in oats. The highest content of PCA was determined in the varieties Oliver 2014 (2.60 mg/kg), Kamil 2014 (2.05 mg/kg), Racoon $2014(1.78 \mathrm{mg} / \mathrm{kg})$. The highest content of FA in oat was determined in the varieties Kroner $6.27 \mathrm{mg} / \mathrm{kg}$, Oliver $2014(5.72 \mathrm{mg} / \mathrm{kg})$ and 100260 CN $2014 \quad(5.66 \mathrm{mg} / \mathrm{kg})$. The highest content of AVN 2c in oat was determined in varieties the Racoon 2014 (288.22 mg/kg), Oliver 2014 $(133.13 \mathrm{mg} / \mathrm{kg})$ and $100260 \quad \mathrm{CN} 2014$ $(109.91 \mathrm{mg} / \mathrm{kg})$. Samples of Racoon 2014 (230.09 mg/kg), Oliver 2014 (153.31 mg/kg) and Kamil $2014(118.38 \mathrm{mg} / \mathrm{kg})$ contain the largest amount of AVN 2p. The highest content of AVN $2 f$ was detected in the varieties Oliver 2014 (292.15 mg/kg), Racoon 2014 (204.98 mg/kg) and Kamil 2014 (180.94 mg/kg). In general, the highest content of all five studied polyphenols was found in the varieties: Oliver 2014, Racoon 2014 and
Kamil 2014. Content of total avenanthramides in this study was the highest in the varieties Racoon $(723.28 \mathrm{mg} / \mathrm{kg})$ followed by Oliver $(578.59 \mathrm{mg} / \mathrm{kg})$ and Kamil (384.17 mg/kg). The Racoon, Oliver, Kamil and $100260 \mathrm{CN}$ from the year 2014 are the most exciting varieties for purpose of cultivation and breeding. The Racoon, Oliver, Kamil and $100260 \mathrm{CN}$ can improve the nutritional and health benefits properties of oats.

Values of PAs (PCA, FA) and AVNs (2c, 2p and $2 \mathrm{f}$ ) of oat flour (LO) and of extruded oatbread were similar. This finding suggests that the biotechnological process for LO preparations retains the nutrition quality of processed oats. The biotechnological production process used does not reduce the content of studied phenolic compounds. Thus, the content of health beneficial substances remains preserved for the consumer. Content of PCA and FA was higher in oat breads as much as in the flour. It is possible to explain by partial 
Table 2. Summary of content (mg/kg) of five analytes in 18 samples of oats (Avena sativa L.) expressed as averages and standard deviations calculated from three replicates.

\begin{tabular}{|c|c|c|c|c|c|c|c|c|c|c|c|c|}
\hline \multirow[b]{2}{*}{ Year } & \multirow[b]{2}{*}{ Variety } & \multicolumn{2}{|l|}{ PCA } & \multicolumn{2}{|l|}{ FA } & \multicolumn{2}{|c|}{ AVN 2c } & \multicolumn{2}{|c|}{ AVN 2p } & \multicolumn{2}{|l|}{ AVN $2 f$} & \multirow{2}{*}{$\frac{\text { AVNs }}{\mathrm{S}}$} \\
\hline & & $\mathbf{m} \pm \mathbf{S T D}$ & $\begin{array}{c}\text { RSD } \\
{[\%]}\end{array}$ & $\mathbf{m} \pm \mathbf{S T D}$ & $\begin{array}{c}\text { RSD } \\
{[\%]}\end{array}$ & $\mathbf{m} \pm$ STD & $\begin{array}{c}\text { RSD } \\
{[\%]}\end{array}$ & $\mathbf{m} \pm$ STD & $\begin{array}{c}\text { RSD } \\
{[\%]}\end{array}$ & $\mathbf{m} \pm$ STD & $\begin{array}{c}\text { RSD } \\
{[\%]}\end{array}$ & \\
\hline \multirow[t]{10}{*}{2014} & Oliver & $2.60 \pm 0.02 a$ & 0.76 & $5.72 \pm 0.09 a$ & 1.52 & $133.13 \pm 3.42 \boldsymbol{b}$ & 2.57 & $153.31 \pm 3.31 \boldsymbol{b}$ & 2.16 & $292.15 \pm 32.12 \boldsymbol{b}$ & 10.99 & 578.59 \\
\hline & $100260 \mathrm{CN}$ & $1.39 \pm 0.04 \boldsymbol{b}$ & 2.67 & $5.66 \pm 0.15 a$ & 2.66 & $109.91 \pm 7.55 \boldsymbol{d}$ & 6.87 & $106.45 \pm 6.77 \boldsymbol{d}$ & 6.36 & $138.75 \pm 7.43 d$ & 5.36 & 355.12 \\
\hline & Kamil & $2.05 \pm 0.21 c$ & 10.3 & $4.72 \pm 0.53 \boldsymbol{b}$ & 11.26 & $84.84 \pm 2.80 c$ & 3.30 & $118.38 \pm 4.42 c$ & 3.74 & $180.94 \pm 5.98 c$ & 3.31 & 384.17 \\
\hline & Racoon & $1.78 \pm 0.18 d$ & 10.29 & $4.98 \pm 0.31 c$ & 6.20 & $288.22 \pm 11.38 \boldsymbol{a}$ & 3.95 & $230.09 \pm 9.47 \boldsymbol{a}$ & 4.11 & $204.98 \pm 6.29 a$ & 3.07 & 723.28 \\
\hline & Bayan 2 & $0.96 \pm 0.07 \boldsymbol{e}$ & 7.63 & $5.37 \pm 0.25 d$ & 4.73 & $73.52 \pm 1.74 e$ & 2.37 & $66.60 \pm 2.11 e$ & 3.17 & $120.40 \pm 2.37 \boldsymbol{e}$ & 1.97 & 260.52 \\
\hline & Hronec & $1.08 \pm 0.01 f$ & 1.7 & $5.08 \pm 0.16 c$ & 3.16 & $52.93 \pm 2.19 \mathrm{~g}$ & 4.15 & $65.71 \pm 3.62$ ef & 5.51 & $94.56 \pm 4.01 \mathrm{~g}$ & 4.25 & 213.19 \\
\hline & Dunajec & $0.88 \pm 0.02 \mathrm{eg}$ & 2.26 & $3.05 \pm 0.08 \boldsymbol{e}$ & 2.77 & $62.58 \pm 1.36 f$ & 2.17 & $71.42 \pm 1.77 \boldsymbol{e}$ & 2.48 & $103.62 \pm 1.16 f g$ & 1.12 & 237.62 \\
\hline & Avenuda & $1.04 \pm 0.10$ ef & 10.9 & $2.81 \pm 0.26 f$ & 9.11 & $74.25 \pm 4.12 e$ & 5.54 & $64.12 \pm 2.95$ ef & 4.61 & $110.61 \pm 2.90$ ef & 2.62 & 248.99 \\
\hline & Važec & $0.78 \pm 0.05 g h$ & 6.74 & $2.51 \pm 0.13 \mathrm{~g}$ & 4.99 & $34.84 \pm 0.52 \boldsymbol{h}$ & 1.50 & $25.45 \pm 1.37 \boldsymbol{h}$ & 5.39 & $42.18 \pm 2.14 \boldsymbol{h}$ & 5.07 & 102.46 \\
\hline & Tatran & $0.88 \pm 0.01$ egh & 0.36 & $2.40 \pm 0.03 g$ & 1.33 & $33.58 \pm 2.22 \boldsymbol{h}$ & 6.61 & $31.37 \pm 0.44 \mathrm{~g}$ & 1.40 & $52.62 \pm 0.43 \boldsymbol{h}$ & 0.81 & 117.57 \\
\hline \multirow[t]{7}{*}{2015} & Avenuda & $0.68 \pm 0.02 a$ & 2.25 & $4.55 \pm 0.04 a$ & 0.94 & $9.57 \pm 0.20 e$ & 2.13 & $3.92 \pm 0.10 e$ & 2.54 & $6.84 \pm 0.46 c$ & 6.79 & 20.33 \\
\hline & AC Percy & $0.65 \pm 0.07 \boldsymbol{b}$ & 11.10 & $3.13 \pm 0.19 \boldsymbol{b}$ & $5 ., 95$ & $10.30 \pm 0.58 \boldsymbol{e}$ & 5.66 & $3.72 \pm 0.09 e$ & 2.34 & $4.39 \pm 0.38 \boldsymbol{d}$ & 8.73 & 18.40 \\
\hline & Avenuda-Atego & $0.57 \pm 0.02 c$ & 2.91 & $3.11 \pm 0.37 \boldsymbol{b}$ & 11.90 & $15.27 \pm 1.56 d$ & 10.25 & $9.17 \pm 0.84 \boldsymbol{d}$ & 9.11 & $9.74 \pm 1.23 \boldsymbol{b}$ & 12.65 & 34.18 \\
\hline & Fussion & $0.53 \pm 0.03 d$ & 5.55 & $2.54 \pm 0.08 c$ & 3.26 & $36.13 \pm 2.08 \boldsymbol{a}$ & 5.75 & $24.29 \pm 0.50 a$ & 2.05 & $16.71 \pm 1.91 a$ & 11.46 & 77.12 \\
\hline & Racoon & Trace & - & $2.43 \pm 0.04 c$ & 1.68 & $27.48 \pm 1.16 \boldsymbol{b}$ & 4.21 & $21.50 \pm 0.41 \boldsymbol{b}$ & 1.88 & $9.38 \pm 0.27 \boldsymbol{b}$ & 2.84 & 58.35 \\
\hline & Expression & Trace & - & $2.37 \pm 0.04 c$ & 1.84 & $20.52 \pm 2.47 c$ & 12.03 & $11.97 \pm 1.26 c$ & 10.48 & $6.37 \pm 0.58 c$ & 9.14 & 38.87 \\
\hline & Izák & $0.79 \pm 0.03 e$ & 3.68 & $1.40 \pm 0.01 d$ & 1.05 & $9.15 \pm 0.39 e$ & 4.24 & $5.06 \pm 0.18 f$ & 3.50 & $5.21 \pm 0.51 d$ & 9.70 & 19.42 \\
\hline \multirow[t]{6}{*}{ CAP } & Kroner & $1,03 \pm 0,11$ & 10.99 & $6.27 \pm 0.54$ & 8.63 & $6.97 \pm 0.05$ & 0.76 & $4.39 \pm 0.33$ & 7.52 & $6.00 \pm 0.35$ & 5.80 & 17.36 \\
\hline & Ravita & $0.88 \pm 0.10$ & 10.84 & $5.66 \pm 0.53$ & 9.32 & $32.31 \pm 2.77$ & 8.58 & $15.33 \pm 1.12$ & 7.28 & $34.64 \pm 2.09$ & 6.05 & 82.28 \\
\hline & Jednota & $0.74 \pm 0.06$ & 8.29 & $4.65 \pm 0.50$ & 10.68 & $22.04 \pm 1.82$ & 8.27 & $10.18 \pm 0.81$ & 7.94 & $21.39 \pm 1.96$ & 9.17 & 53.61 \\
\hline & Vince & $0.80 \pm 0.03$ & 3.34 & $4.43 \pm 0.07$ & 1.57 & $27.07 \pm 1.00$ & 3.70 & $12.98 \pm 0.20$ & 1.56 & $21.55 \pm 0.80$ & 3.73 & 61.61 \\
\hline & Oatbred & $1.32 \pm 0.11$ & 8.63 & $3.72 \pm 0.25$ & 6.70 & $48.61 \pm 2.04$ & 4.20 & $64.73 \pm 2.60$ & 4.01 & $75.28 \pm 2.39$ & 3.18 & 188.62 \\
\hline & Flour & $0.84 \pm 0.03$ & 3.32 & $3.48 \pm 0.20$ & 5.79 & $52.79 \pm 2.37$ & 4.50 & $67.16 \pm 2.87$ & 4.28 & $78.49 \pm 3.67$ & 4.67 & 198.44 \\
\hline
\end{tabular}

CAP - commercially available products;

Different letters indicate significant differences at $P<0.05$.

hydrolysis of bound PAs during extrusion (Kováčová et al. 2007). It is stated that the quantity of free ferulic acidin grains is $0.1-0.5 \%$, most of it bound with polysaccharides and sterols (Zhao et al. 2008).

In the study by $\mathrm{Xu}$ et al. (2009) was reported that gallic acid, vanillic acid, caffeic acid, ferulic acid, and $p$-coumaric acid are the main PAs in oats. The content of FA in oat bran was $33 \mathrm{mg} / 100 \mathrm{~g}$ (Boz 2015). In the study by Chen et al. (2018) was reported that FA was in range $1.32-18.98 \mu \mathrm{g} / \mathrm{g}$. The concentration of $p$-coumaric acid in oats is not very much published. There are studies of the presence of $p$-coumaric acid in other cereals. The $p$-coumaric acid $(97.87-211.03 \mathrm{mg} / \mathrm{kg})$ and $o$-coumaric acid $(126.53-575.87 \mathrm{mg} / \mathrm{kg})$ were determined in the corn (Hung 2014). The intervention diet (60 $\mathrm{g}$ oat bran) contained $28.6 \mathrm{mg}$ of total phenolics $(24 \%$ in the soluble fraction), with FA being the predominant PAs (16.8 $\mathrm{mg}$ ) followed by PCA $(3.3 \mathrm{mg})$ and the three AVNs totally amounting to $2.5 \mathrm{mg}$ (Schär et al. 2018). FA, PCA and AVN 2p accounted only for small percentages of the total excreted phenolics and AVNs $2 \mathrm{f}$ and $2 \mathrm{c}$ were not detected, suggesting that these dietary forms are subject to extensive metabolism (Schär et al. 2018). AVNs content in whole oat extracts was 3.7 to $48.41 \mathrm{mg} / \mathrm{kg}$ for AVN 2c, 1.05 to $43.77 \mathrm{mg} / \mathrm{kg}$ for $2 \mathrm{p}$ and 3.66 to $58.63 \mathrm{mg} / \mathrm{kg}$ for $2 \mathrm{f}$ in the varieties of oats from Canada (Chu et al. 2013). In oat, values of AVNs were as follows: 1.16 to $70.06 \mu \mathrm{g} / \mathrm{g}$ for AVN 2c, 2.3 to $74.7 \mu \mathrm{g} / \mathrm{g}$ for AVN $2 \mathrm{p}$ and 1.11 to $69.74 \mu \mathrm{g} / \mathrm{g}$ for AVN 2f (Chen et al. 2018). The latter results indicate that low amount of hydroxycinnamic acids and high amount of hydroxybenzoic acids may be characteristics of the oats (Avena nuda L.) from China (Chen et al. 2018). AVNs content of oat milling fractions ranged from 323.7 to $775.5 \mu \mathrm{g} / \mathrm{g}$, while the free phenolic acids content was much lower $(103.5-194.6 \mu \mathrm{g} / \mathrm{g})$. The study by Li et al. (2017) reported that the concentrations of $A V N 2 f$ were higher than those of the other two AVNs. Concentrations of total AVNs in this study ranged from 22.1 to $471.2 \mathrm{mg} / \mathrm{kg}$. For comparison, concentrations of total AVNs in our study ranged from 17.36 to $723.28 \mathrm{mg} / \mathrm{kg}$, which presents high concentration values of AVNs.

In the varieties of oat were observed year-on-year fluctuations of selected phenolic compounds. In the oat varieties from the year 2014 , the analytes were 
determination in significantly higher concentration than in the oat varieties from the year 2015 . This observation was caused by the meteorology. In March-July 2014, higher average temperatures and lower precipitations (\%) were measured, reflecting significantly different concentrations of all studied polyphenols.

\section{Statistical analysis}

The data were expressed as the means with standard deviation and were analyzed by the analysis of variance (one way ANOVA) and Pearson product-moment correlation coefficient. Statistical significance was defined as $P<0.05$. The analysis was carried out with statistical software IBM SPSS 22 using the Post Hoc test LSD.

\section{Conclusions}

Oat is a cereal with a rich source of health beneficial phytochemicals. We evaluated the contents of phenolic compounds present in oat grown in Slovakia and selected the most interesting varieties with a high content of nutritional values. A simple reversed-phase HPLC-DAD method was developed for simultaneous determination of PCA, FA, AVNs 2c, 2p and 2f. The separation of selected phenolic compounds by HPLC was rapid, efficient and reproducible, and the method presented acceptable results for sensitivity, linearity, precision, and accuracy. The study has shown that the oat varieties grown in 2014 have a significantly higher content of selected polyphenols than the oat varieties of 2015 . The most exciting varieties for purpose of cultivation and breeding are Oliver, Racoon, Kamil and $100260 \mathrm{CN}$. The HPLC method has potential to be used in analysis of oats and product of oats since currently there is an interest on characterization and determination of biologically active compounds in cereal.

\section{Acknowledgement}

This work was financially supported by the grants KEGA 006UCM-4/2018, VEGA 1/0919/17, VEGA 1/0534/16 and APVV-17-0113.

\section{References}

Boz H (2015) Phenolic amides (avenanthramides) in oats A review. Czech J. Food Sci. 33: 399-404.

Emmons ChL, Peterson DM, Paul GL (1999) Antioxidan capacity of oat (Avena sativa L.) extracts. 2. In vitro antioxidant activity and contents of phenolic and tocol antioxidants. J. Agric. Food. Chem. 47: 4894-4898.

Hung PV (2014) Phenolic compounds of cereals and their antioxidant capacity. Crit. Rev. Food Sci. Nutr. 56: 25-35.

Chemat F, Rombaut N, Meullemiestre A, Turk M, Perino S, Fabiano-Tixier AS, Abert-Vian M (2017) Review of green food processing techniques. Preservation, transformation, and extraction. Innov. Food Sci. Emerg. Technol. 41: 357-377.

Chen CY, Milbury PE, Collins FW (2007) Avenanthramides are bioavailable and have antioxidant activity in humans after acute consumption of an enriched mixture from oats. J. Nutrition 137: 1375-1382.

Chen CY, Milbury PE, Kwak HK, Collins FW, Samuel P, Blumberg JB (2004): Avenanthramides and phenolic acids from oats are bioavailable and act synergistically with vitamin $\mathrm{C}$ to enhance hamster and human LDL resistance to oxidation. J. Nutrition 134: 1459-1466.

Chen CY, Wang L, Wang R, Luo X, Li Y, Li J, Li Y, Chen Z (2018) Phenolic contents, cellular antioxidant activity and antiproliferative capacity of different varieties of oats. Food Chem. 239: 260-267.

Chu Y, Wise ML, Gulvady AA, Chang T, Kendra DF, Klinken BJ, Shi Y, O'Shea M (2013) In vitro antioxidant capacity and anti-inflammatory activity of seven common oats. Food Chem. 139: 426-431.

Kováčová M, Malinová E (2007) Ferulic and coumaric acids, total phenolic compounds and their correlation in selected oat genotypes. Czech J. Food Sci. 6: 325-332.

Li X, Li M, Ling A Hu X, Ma Z, Liu L, Li Y (2017) Effects of genotype and environment on avenanthramides and antioxidant activity of oats grown in northwestern China. J. Cereal Sci. 73: 130-137.

Maliarová M, Mrázová V, Havrlentová M, Sokol J (2015) Optimization of parameters for extraction of avenanthramides from oat (Avena sativa L.) grain using response surface methodology (RSM). J. Braz. Chem. Soc. 26: 2369-2378.

Menon R, Gonzalez T, Ferruzzi M, Jackson E, Winderl D, Watson J (2016) Oats -from farm to fork. Adv. Food Nutr. Res. 77: 1-55.

Multari S, Pihlava JM, Ollennu-Chuasam P, Hietaniemi V, Yang B, Suomela JP (2018) Identification and quantification of avenanthramides and free and bound phenolic acids in eight cultivars of husked oat (Avena sativa L.) from Finland. J. Agric. Food Chem. 66: 29002908.

Ren Y, Yang X, Niu X, Liu S, Ren G (2011) Chemical characterization of the avenanthramide-rich extract from oat and its effect on D-galactose-induced oxidative stress in mice. J. Agric. Food Chem. 59: 206-211. 
Schär MY, Corona G, Soycan G, Dine C, Kristek A, Alsharif SNS, Behrends V, Lovegrove A, Shewry PR, Spencer JPE (2018) Excretion of avenanthramides, phenolic acids and their major metabolites following intake of oat bran. Mol. Nutr. Food Res. 62: 1700499.

Shewry PR, PiironenV, Lampi AM, NyströmL, Li L, Rakszegi M, Fraś A, Boros D, Gebruers K, Courtin CM, Delcour JA, Andersson AAM, Dimberg L, Bedő Z, Ward JL (2008) Phytochemical and fiber components in oat varieties in the HEALTHGRAIN diversity screen. J. Agric. Food. Chem. 56: 9777-9784.

Thomas M, Kim S, Guo W, Collins WF, Wise ML, Meydani M (2018) High levels of avenanthramides in oat-based diet further suppress high fat diet-induced atherosclerosis in Ldlr ${ }^{-/-}$Mice. J. Agric. Food. Chem. 66: 498-504.
Whitehead A, Beck EJ, Tosh S, Wolever TM (2014) Cholesterol-lowering effects of oat $\beta$-glucan: a metaanalysis of randomized controlled trials. Am. J. Clin. Nutr. 100: 1413-1421.

Xu JG, Tian CR, Hu QP, Luo JY, Wang XD, Tian XD (2009) Dynamic changes in phenolic compounds and antioxidant activity in oats (Avena nuda L.) during steeping and germination. J. Agric. Food Chem. 57: 10392-10398.

Zeng Z, Liu C, Luo S, Chen J, Gong E (2016) The profile and bioaccessibility of phenolic compounds in cereals influenced by improved extrusion cooking treatment. PLoS One 11: e0161086.

Zhao Z, Moghadasian MH (2008) Chemistry, natural sources, dietary intake and pharmacokinetic properties of ferulic acid: A review. Food Chem. 109: 691-702. 